\title{
HOMAGE TO RITA LEVI-MONTALCINI, THE QUEEN OF MODERN NEUROSCIENCE
}

\author{
George N. Chaldakov' and Luigi Aloe ${ }^{2}$ \\ ${ }^{1}$ Laboratory of Cell Biology, Medical University, Varna, Bulgaria and ${ }^{2}$ Institute of Cell Biology and \\ Neurobiology, Consiglio Nazionale delle Ricerche (CNR), Rome, Italy
}

The first cell growth factor, nerve growth factor (NGF), was discovered by Rita Levi-Montalcini (RLM) in the early 1950's in Washington University in Saint Louis, Missouri, USA. Originally identified as neurite outgrowth-stimulating factor, later studies revealed that non-neuronal cells, including immune cells, endothelial cells, cardiomyocytes, pancreatic beta cells, prostate epithelial cells and adipose tissue cells, are also targets for and/or sources of NGF. Nerve growth factor is well recognized at present to mediate multiple biological phenomena, ranging from the neurotrophic through immunotrophic and epitheliotrophic to metabotrophic effects. Consequently, NGF and other members of the neurotrophin family are implicated in the pathogenesis of a large spectrum of neuronal and non-neuronal diseases, ranging from Alzheimer's and other neurodegenerative diseases to atherosclerosis and other cardiometabolic diseases. Recent studies demonstrated the therapeutic potentials of NGF in these diseases including ocular and cutaneous diseases. Whereas NGF TrkA receptor antagonists emerged as novel drugs for pain, prostate and breast cancer, and urinary bladder syndromes. Here we briefly describe (i) the "unpredictable" ideogenesis of the discovery of NGF, and (ii) our scientific and human experience working in RML's laboratory for 15 years (GNC) and over 40 years (LA). Biomed Rev 2012; 23: 1-7.

Key words: nerve growth factor, TrkA, p75 ${ }^{\mathrm{NTR}}$, neuronal cells, non-neuronal cells, disease, therapy

\section{INTRODUCTION}

Rita Levi-Montalcini (RLM) was born April 22, 1909 in Turin, Italy, where received her medical degree from the University of Turin in 1936. The same year she entered the Institute of Anatomy as postgraduate student of Professor Giuseppe Levi, a well-known neuroanatomist and tutor of two other future Nobel Prize winners in Physiology or Medicine, Salvadore
Luria (in 1969) and Renato Dulbecco (in 1975). During her early postgraduate years, she studied the relationship between the developing nervous system and its peripheral targets and observed that many sensory neurons died during normal development, and that the limb bud extirpation caused an increase in the number of nerve cell death. The results of these studies

Correspondence to Dr Luigi Aloe, Institute of Cell Biology and Neurobiology, Consiglio Nazionale delle Ricerche (CNR), Rome, Italy. Tel: +39 065017 03240; Fax: +39 065017 03313; E-mail: aloe@inmm.cnr.it 
lead her to the hypothesis that the failure of neurons to thrive in the absence of peripheral target was because of a degenerative process rather than a failure of differentiation, as had previously been hypothesized by Victor Hamburger, a well-known neuroembryologist working at the Department of Zoology, Washington University in St. Louis, MO. In 1946, Hamburger invited Levi-Montalcini to join his group to reinvestigate their scientific disagreements. In their initial published work LeviMontalcini and Hamburger (1951) prospected the hypothesis that the nerve-target interactions are reciprocally competitive in the sense that developing neurons depend on feedback (retrograde) signals from the peripheral tissues that are required for neuronal survival. These seminal observations and hypothesis pawed the way to the discovered of programmed cell death (in the today's context, the apoptosis), and later the discovery of nerve growth factor (NGF).

\section{THE ROAD OF DISCOVERY}

At the end of the nineteenth century, it was envisaged by Santiago Ramon y Cajal but has not been proven that life at the neuronal level requires trophic support. The proof was obtained by work initiated by Rita Levi-Montalcini in 1949. Then she first saw the results of Elmer Bueker, a former student of Hamburger, showing the effect of transplanting mouse sarcoma 180 into a chick embryo. Bueker observed that upon transplantation, the tumor stimulated the growth of fibers from neurons of the sensory ganglia into the tumor, just as they would have done into transplanted limbs and even more vigorously. $\mathrm{He}$ interpreted this result writing that the tumor transplantation effect was greater because the tumor provided a larger target area for the cells to expand than a limb would have. This interpretation did not convince Levi-Montalcini and following the suggestion of Hamburger then decided to repeat this experiment. She found the same result, but reached a different interpretation, hypothesizing that the transplanted tumor tissue induced hyperinnervation of internal chick organs by releasing a diffusible agent that stimulated the growth and differentiation of developing nerve cells. Using in vitro analysis, she studied the effect of this extract on isolated sensory and sympathetic nerve cells and clearly demonstrated the direct stimulating action of the tumor extract on nerve growth and named initially this yet unknown molecule nerve growth-stimulating factor, later termed NGF (Levi-Montalcini and Hamburger,1951; Levi-Montalcini 1952; Levi-Montalcini and Booker 1960). In attempt to purify the tumor-derived factor, Levi-Montalcini and Stanly Cohen used snake venom as a rich source of phosphodiesterase, a nucleic acid-destroying enzyme, for the separation of nucleic acids and protein fractions in the tumor material. To their great surprise, the tumor fraction containing the snake venom was several thousand-fold more potent than control tumor homogenate in promoting nerve growth, both in vitro and in vivo. Further on the road of discovery, LeviMontalcini and Cohen examined the mammalian homologue of the snake venom, the salivary gland, and found that the male mouse submandibular glands were an even richer source of the same nerve growth-stimulating activity found in both the tumor and the snake venom. Thus male mouse submandibular glands appeared to be a new and possibly largest source of NGF providing the possibility to isolate and purified consistent amount of this intriguing biomolecule. In effect, such an unpredictable experimental cascade (from tumor via snake venom to salivary glands) resulted in the discovery of NGF in 1951, a heuristic phenomenon marked by a rare combination of scientific reasoning, intuition, and chance.

\section{THE NGF AND ITS RECEPTORS}

Since its discovery, NGF becomes one of the best-characterized members of the protein family of neurotrophic factors designated neurotrophins, including NGF, BDNF, NT-3/4, NT-5, NT-6, and NT-7) (Aloe and Calzá, 2004). The biological action of NGF is mediated by $(i)$ the high-affinity receptor TrkA (tropomyosin-related kinase receptor A; also known as tyrosine kinase receptor), and (ii) the low-affinity receptor termed $\mathrm{p} 75$ (pan)neurotrophin receptor (p75 ${ }^{\mathrm{NTR}}$ ). In most cases, TrkA expression exerts protective actions on diseases involving degeneration of NGF target cells. In these diseases, the balance of TrkA and $\mathrm{p} 75^{\mathrm{NTR}}$ signaling pathways is altered through different mechanisms including co-receptor modulation. TrkA receptor agonists may provide alternatives in therapy of neurodegenerative and psychiatric diseases (see below). Of note, the NGF precursor proNGF induces apoptosis through $\mathrm{p} 75^{\mathrm{NTR}}$ (Fahnestock et al, 2004).

\section{NGF AND NON-NEURONAL CELLS}

As often occurs, the framework of an initial conception of the physiological role of a newly discovered molecule extends in the light of emerging findings. This was also the case with NGF. During some 25 years after its discovery, for example, there have been few reasons given to indicate that NGF acts on non-neuronal cells. Thus, in 1975, Luigi Aloe and LeviMontalcini have made a remarkable experiment demonstrating that treatment of newborn rats with NGF caused a systemic 
increase in the number of mast cells. This seminal finding, published in Brain Research in 1977, has triggered the study on neuroimmune connections, leading to today's accumulation of compelling evidence that NGF is wider than the neuron (paraphrasing Emily Dickinson's The brain is wider than the $s k y)$. That is, in addition to its neurotrophic function, this talented molecule influences the survival and activity of a large number of "unpredictable", non-neuronal cells such as immune cells, fibroblasts, epithelial cells, pancreatic beta cells, adipose tissue cells, and cardiomyocytes (Aloe et al, 1994; Aloe and Chaldakov, 1999; Aloe and Calzá, 2004, Marinova et al, 2004; Larrieta et al, 2006; Sornelli et al, 2009; Meloni et al, 2010; Lam et al, 2012). Such non-neuronal actions of NGF, also of other neurotrophic factors subsequently discovered, open novel avenues in the study of neurobiology, namely, neuroimmunology (Aloe and Levi-Montalcini, 1977) and, recently, neuroadipology (Chaldakov et al, 2010). Thus, we witness, appreciate, and, hopefully, contribute to an exciting time in the field of integrative physiology (systems biology) of NGF, we also termed "NGF-ome". Pioneering studies published by Enrico Alleva in collaboration with Levi-Montalcini and Aloe revealed a pivotal role of NGF in aggressive and anxiety-like behaviors (Alleva et al, 1993).

Altogether, "the submerged areas of the NGF iceberg loom very large", Rita Levi-Montalcini (1987) stated in her Nobel prize lecture reviewing 35 years of research on NGF.

\section{THE THERAPEUTIC NGF}

The treatment of diabetic polyneuropathy was one of earliest indication sought for clinical trial of NGF. The first results of these studies are at the moment controversial. Subsequent studies investigating the effect of NGF administration in rodent forebrain cholinergic neurons and behavior and memory performances lead to the hypothesis that NGF may be useful to protect these neurons that are known to degenerate in brain of subjects affected by Alzheimer's disease. While the therapeutic potential of NGF in the treatment of neurotrophic corneal ulcers, skin ulcers, glaucoma and Alzheimer's disease (Aloe et al, 2004, 2012) seems clearly demonstrated, the use of NGF as drug is to some extend limited for its not fully established pharmacokinetics and the high cost associated with the production of human recombinant NGF. These obstacles have driven the scientific community also toward the identification of small molecules (NGF mimetics) with drug-like properties. These molecules may ( $i$ ) directly bind to NGF receptors causing their activation, (ii) enhance the release of endogenous NGF, and/ or (iii) influence intracellular signaling pathways.

Several therapeutic strategies to delivery NGF in animal models and in human diseases have been explored and clinical steps have been attempted, while others are currently in progress to evaluate whether NGF and/or TrkA receptor agonists can prevent or protect against cell degeneration in the nervous system, visual system, cutaneous and myocardial tissue (Yuen et al, 1996; Apfel et al, 1998; Lambiase et al, 1998; Bernabei et al, 1999; Landi et al, 2003; Chiretti et al, 2002; Lambiase et al, 2009a; Lambiase et al, 2009b; Meloni et al, 2010; Lam et al, 2012; Aloe et al, 2012). And most likely to exert therapeutic effects on cardiometabolic diseases such as atherosclerosis, obesity, type 2 diabetes and metabolic syndrome (Chaldakov et al, 2004, 2009; Chaldakov, 2011). Contrary, TrkA receptor antagonists emerged as novel drugs for prostate (Weeraratna et al, 2000) and breast (Romon et al, 2010) cancer, bladder syndromes (Ochodnický et al, 2011) and various pain conditions (Mantyh et al, 2011). Intriguingly, NGF may contribute to romantic love (Emanuele et al, 2006; Emanuele, 2011).

The experimental approach also includes recombinant human neurotrophin application, direct gene transfer using (non-) viral vectors, the implantation of ex vivo genetically engineered cells secreting neurotrophic factors, and the grafting of neural stem progenitor cells. Every second years, experts in the field of NGF and other neurotrophic factors organize an international scientific meeting in different countries.

\section{THE QUEEN OF NEUROSCINECE}

Rita Levi-Montalcini has published more than 200 scientific articles which contributed in depth to the excellence of modern neuroscience. She had an unlimited interest both in scientific and human activities and is a member of numerous national and international scientific academies. In 1968 she was elected member of the National Academy of Science of USA. In 1972 - member of the American Association of Art and Science. In 1986 she was awarded Albet Lasker Award for Basic Medical Research, a precursor of Nobel prize she received in 1986 (Photograph 1).

In 1974 she was the first woman elected member of the Pontifical Academy of Sciences of the Vatican. Then Dr Tom Woolsey, the George H. and Ethel R. Bishop Scholar in Neuroscience at the School of Medicine, said: "When Levi-Montalcini was appointed to the Pontifical Academy by Pope Paul VI, the protocol required her to kneel and kiss the Pope's hand. Rita said: "I simply stood and shook the Pope's hand." In her independence and determination, she was a model for all scientists". 


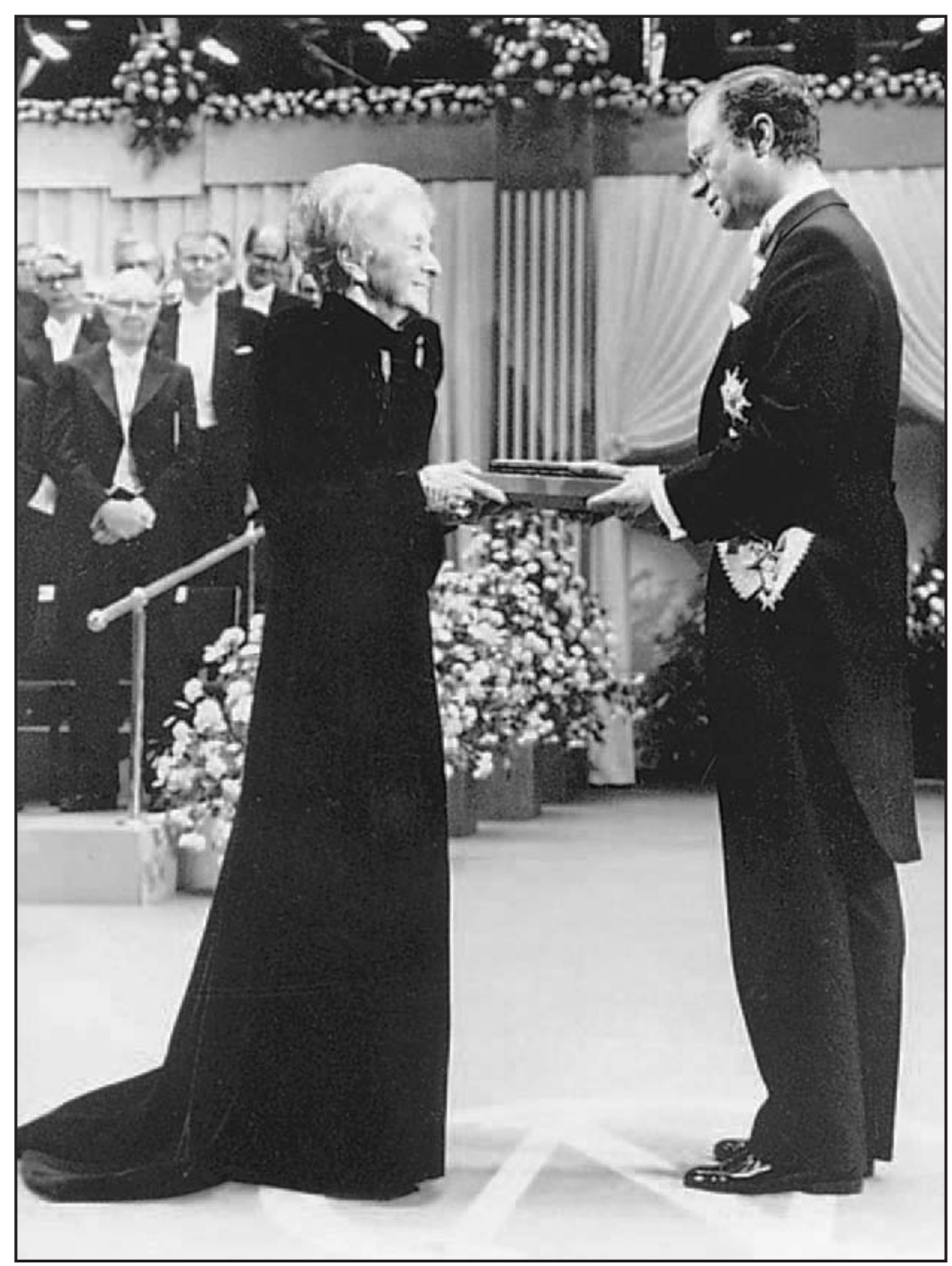

Photograph 1. The Nobel Prize Award Ceremony, 10 December 1986, Stockholm: Rita Levi-Montalcini receives the Nobel Prize form King Carl Gustaf XVI of Sweden.

In 2001 RLM was nominated Senator of the Italian Parliament. She wrote several books: The Praise of Imperfection, her autobiography (dedicated to her $100^{\text {th }}$ Anniversary, GNC wrote In Praise of Perfection published in Bulgarian journal InSpiro volume 6, 2009); The Saga of Nerve Growth Factor, an anthology of key scientific papers on this subject by herself and others (Levi-Montalcini, 1997); Ninety Years in the Galaxy of the Mind, which described her continuing research of the brain and presented a system of ethics of future generations; Cantico di una Vita (Song of Life), a series of about 200 letters written to her mother during the years she made her key discoveries (Levi-Montalcini, 1996; Levi-Montalcini, 1998; Levi-Montalcini, 2000).

\section{THE COLLABORATORS}

During her long scientific life, numerous young and senior scientists worked in RLM's laboratory. Many of them collaborated with her with long and short periods but contributed very little to the NGF studies. Others like Enrico Alleva in Italy and Ralph Bradshaw in USA gave novel contributions to the to the NGF studies. However, reading The Saga of Nerve Growth Factor and her numerous scientific publications, one can come to the conclusion that she had three major collaborators, Stanley Cohen (1953-1959), Pietro Angeletti (1959-1970), and Luigi Aloe (1968-2010).

Stanley Cohen, a biochemist contributed to study the early biochemical properties of the tumor extract and was the first 
to purify the NGF from the snake venom and from the mouse salivary gland and to produce the anti-NGF antibodies. He shared with Levi-Montalcini the Nobel Price in 1986 for the discovered the epidermal growth factor.

Pietro Angeletti, a pathologist with an excellent preparation in biochemistry, made a substantial contribution to the study of NGF purification and to analysis of the spectrum of action of NGF in the peripheral nervous system and of the mechanism of immunosympathecotomy during early postnatal life.

Luigi Aloe (LA) first met Rita Levi-Montalcini in April 1967, at the Instituto Superiore of Sanità in Rome for an interview, while she was observing under the microscope the effect of anti-NGF antibody administration on the superior cervical ganglia of mice. The interview lasted about 20 minutes and two weeks later she called him asking if he would accept to work in her Laboratory in the Department of Zoology of the Washington University in St. Louis, Missouri, USA, for 6 months to take care of raising cockroaches for her studies on the insect nervous system. Luigi Aloe accepted her proposal, thereafter the 6 months became 12, then two years and, consequently, over 40 years. He contributed to identification of new NGF target cells within and outside the nervous system, particularly in immune cells, endocrine system and adipose tissue (as described above in NGF AND NON-NEURONAL CELLS). In the last few years, LA, in collaboration with clinicians, discovered that NGF is an important therapeutic molecule for healing the corneal, pressure and diabetic ulcers, as well as degenerating retinal cells in glaucoma and maculopathy. This latter observation has proved to be useful also for LeviMontalcini herself who suffers of the latter ocular disorder.

In 2002 LA organized the 7th International Meeting on "NGF and related molecules in

Health and Disease" in Modena, Italy (Chaldakov, 2002); in 2004 "Clinical Applications of NGF" Meeting in Rome, and another Rome meeting to celebrate the 100 years of LeviMontalcini, on 21 April 2009 (see Photograph 2).

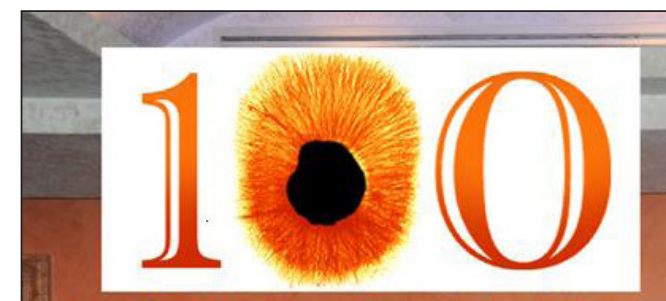

One Day Meeting on Nerve Growth Factor: From sarcoma 180 to clinical application DEDICATED TO RITA LEVI MONTALCINI

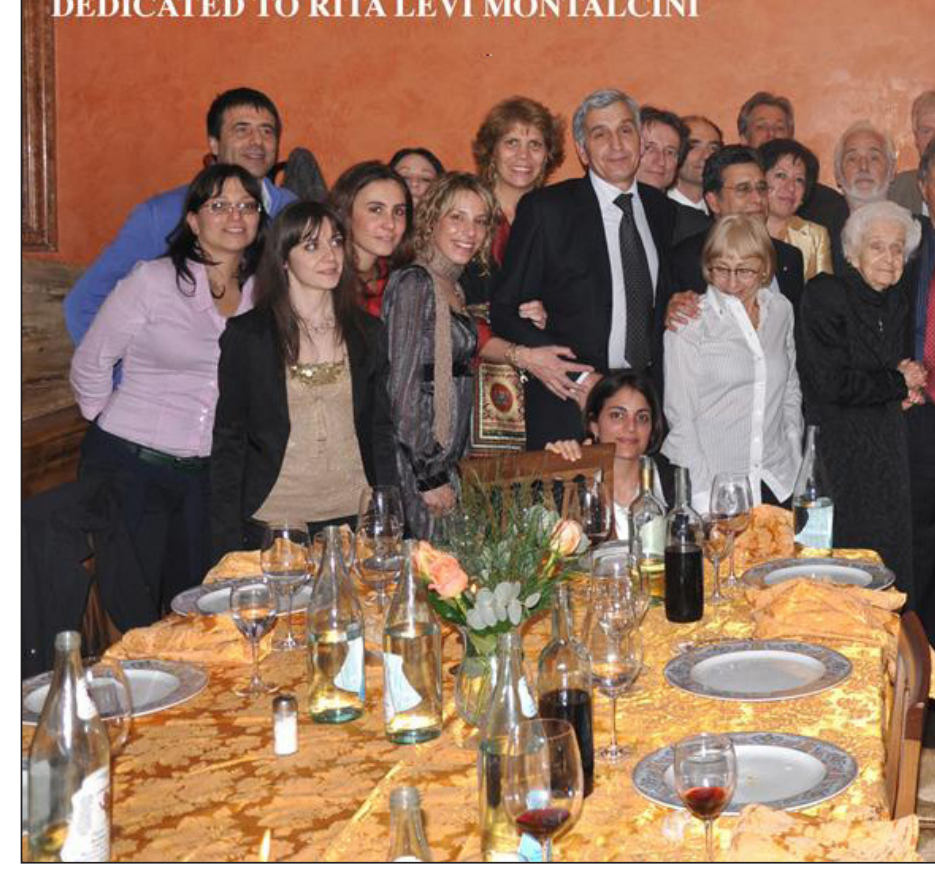

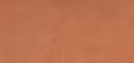
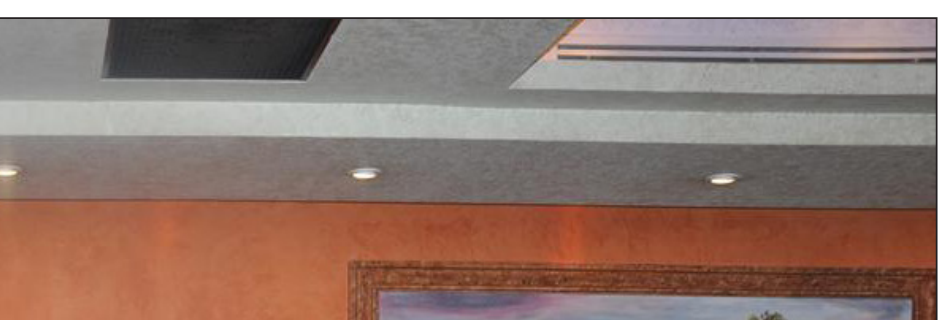

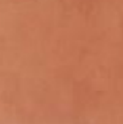

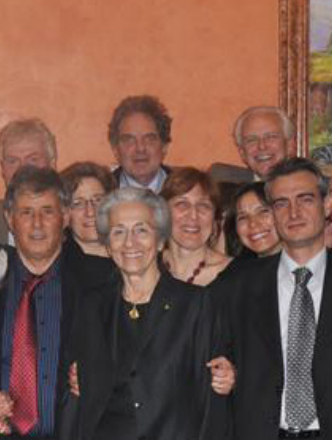

9
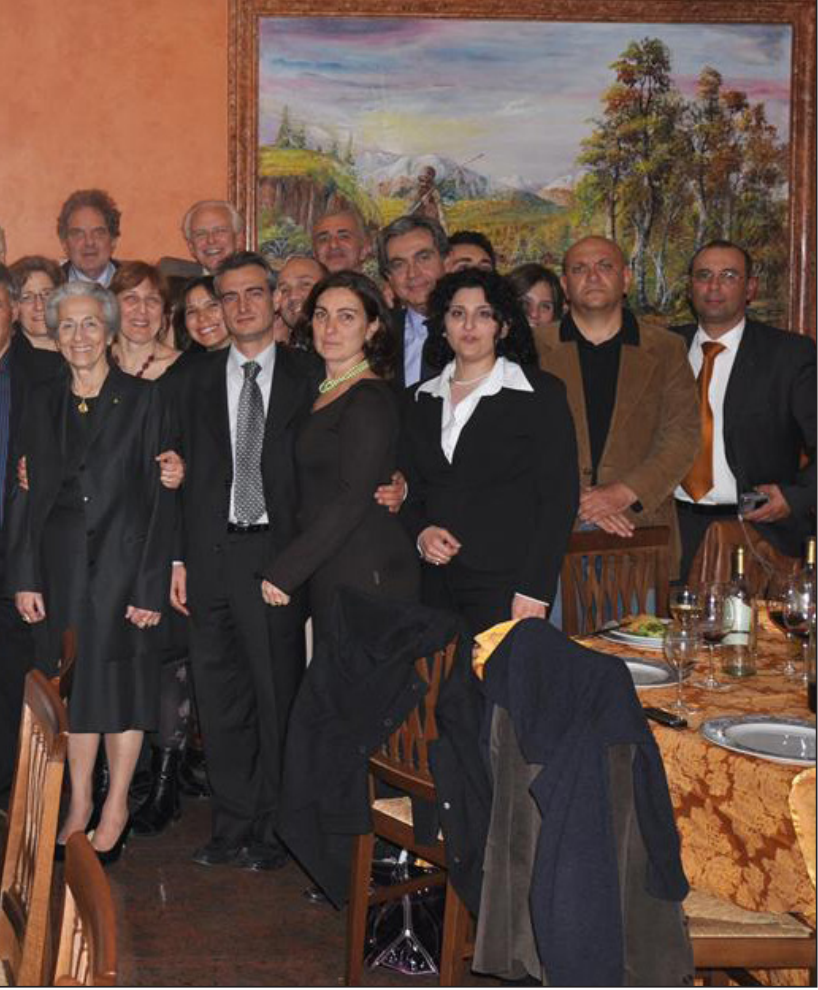

Photograph 2. Rita Levi-Montalcini and participants of the Rome-2009 meeting dedicated to her $100^{\text {th }}$ birthday. 


\section{RESULTS OF A DREAM}

During his student life at the Medical University, Varna, Bulgaria, one of us (GNC) used to work four years (1962-1966) as research associated at the Department of Pharmacology. It was that period of time when he - for the first time - met in libro Rita Levi-Montalcini, reading her first NGF articles. Since then he has being infected by this talented molecule, and thought how to reach her Institute in Rome, Italy. Although some colleagues told him that it is very much difficult pursuit, he continued to believe in his dream. On its road, in 1997 he has applied for NATO Research Fellowship, which required acceptance letter by the host institution. Obviously, his dream asked Luigi Aloe about and he provided him with such a letter, and consequently awarded a fellowship allowing him appeared in the Institute of Neurobiology, CNR, Rome, in June 1998. During this first four months there as well as almost each year further on, he was honored of meeting in vivo many times Rita Levi-Montalcini.

\section{ACKNOWLEDGMENTS}

We express our gratitude to all colleagues who contributed with their studies to the expanding knowledge of biologic actions of NGF and its clinical applications.

\section{REFERENCES}

1. Alleva E, Aloe L, Bigi S. An updated role for nerve growth factor in neurobehavioural regulation of adult vertebrates. Rev Neurosci 1993; 4: 41-62.

2. Aloe L, Bracci-Laudiero L, Alleva E, Lambiase A, Micera A, Tirassa P. Emotional stress induced by parachute jumping changes blood nerve growth factor levels and the distribution of nerve growth factor receptors in lymphocytes. Proc Natl Acad Sci USA 1994; 91:10440-10444.

3. Aloe L, Chaldakov GN, editors. Nerve Growth Factor in Health and Disease. Biomed Rev 1999; 10: 1-113.

4. Aloe L, Calzà L, editors. NGF and Related Molecules in Healthy and Disease. Prog Brain Res 2004; 146: 1-312.

5. Aloe L, Levi-Montalcini R. Mast cells increase in tissues of neonatal rats injected with the nerve growth factor. Brain Res 1997; 133: 358-366.

6. Aloe L, Skaper SD, Leon A, Levi-Montalcini R. Nerve growth factor and autoimmune diseases. Autoimmunity 1994; 19:141-150.

7. Aloe L, Tirassa P, Lambiase A. The topical application of nerve growth factor as a pharmacological tool for human cornea and skin ulcers. Pharmacol Res 2008; 57: 253-258.
8. Aloe L, Rocco ML, Bianchi P, Manni L. Nerve growth factor: from the early discoveries to the potential clinical use. J Transl Med 2012; 10: 239. doi: 10.1186/1479-587610-239.

9. Apfel SC, Kessler JA, Adornato BT., Litchy W.J., Sanders C, Rask CA., and the NGF study Group. Recombinant human nerve growth factor in the treatment of diabetic polyneuropathy. Neurology 1998; 51: 695-702.

10. Bernabei R, Landi F, Bonini S, Onder G, Lambiase A, Pola R, Aloe L. Effect of topical application of nerve growth factor on pressure ulcers. Lancet 1999; 307: 354.

11. Chaldakov GN. NGF-2002: more powerful than NGF1951. Biomed Rev 2002; 13: 67-69.

12. Chaldakov GN, Fiore M, Stankulov IS, Manni L, Hristova MG, Antonelli A, Ghenev PI, Aloe L. Neurotrophin presence in human coronary atherosclerosis and metabolic syndrome: a role for NGF and BDNF in cardiovascular disease? Prog Brain Res 2004; 146: 279-289.

13. Chaldakov GN, Tonchev AB, Aloe L. NGF and BDNF: from nerves to adipose tissue, from neurokines to metabokines. Relevance to neuropsychiatric and cardiometabolic diseases. Riv Psichiatr 2009; 44: 79-87.

14. Chaldakov GN, Fiore M, Tonchev AB, Aloe L. Neuroadipology: a novel component of neuroendocrinology. Cell Biol Int 2010; 34:1051-1053.

15. Chaldakov G. The metabotrophic NGF and BDNF: an emerging concept. Arch Ital Biol 2011;149:257-263.

16. Chiaretti A, Piastra M, Caresta E, Nanni L, Aloe L. Improving ischaemic skin revascularisation by nerve growth factor in a child with crush syndrome. Arch Dis Child 2002; 87: 446-448.

17. Emanuele E, Politi P, Bianchi M, Minoretti P, Bertona M, Geroldi D. Raised plasma nerve growth factor levels associated with early-stage romantic love. Psychoneuroendocrinology 2006; 31:288-294.

18. Emanuele E. NGF and romantic love. Arch Ital Biol 2011;149:265-268.

19. Fahnestock M, Yu G, Coughlin MD. ProNGF: a neurotrophic or an apoptotic molecule? Prog Brain Res 2004;146:101-110.

20. Lam NT, Currie PD, Lieschke GJ, Rosenthal NA, Kaye DM. Nerve growth factor stimulates cardiac regeneration via cardiomyocyte proliferation in experimental heart failure. PLoS One 2012; 7:e53210.

21. Lambiase A, Rama P, Bonini S, Caprioglio G, Aloe L. Topical treatment with nerve growth factor for corneal 
neurotrophic ulcers. New Engl JMed 1998; 338:1174-1180.

22. Lambiase A, Aloe L, Centofanti M, Parisi V, Mantelli F, Colafrancesco V, Manni GL, Bucci MG, Bonini S, Levi-Montalcini R. Experimental and clinical evidence of neuroprotection by nerve growth factor eye drops: Implications for glaucoma. Proc Natl Acad Sci USA 2009a; 106: 13469-13474.

23. Lambiase A, Coassin M, Tirassa P, Mantelli F, Aloe L. Nerve growth factor eye drops improve visual acuity and electrofunctional activity in age-related macular degeneration: a case report. Ann Inst Super Sanita 2009b; 45: 439-442.

24. Landi F, Aloe L, Russo A, Cesari M, Onder G, Bonini S, et al. Topical treatment of pressure ulcer with nerve growth factor: a randomized clinical trial. Ann Intern Med 2003; 139: 635-637.

25. Larrieta ME, Vital P, Mendoza-Rodríguez A, Cerbón M, Hiriart M. Nerve growth factor increases in pancreatic beta cells after streptozotocin-induced damage in rats. Exp Biol Med (Maywood) 2006; 231:396-402.

26. Levi-Montalcini R, Hamburger V. Selective growthstimulating effects of mouse sarcoma on the sensory and sympathetic nervous system of the chick embryo. $J$ Expt Zool 1951; 116: 321-361.

27. Levi-Montalcini R. Effects of mouse tumor transplantation on the nervous system. Ann NY Acad Sci 1952: 55: 330-343

28. Levi-Montalcini R, Booker B. Excessive growth of the sympathetic ganglia evoked by a protein isolated from the mouse salivary glands. Proc Natl Acad Sci USA 1960; 46: 373-384.

29. Levi-Montalcini R. The nerve growth factor: 35 years later. Science 1987; 237: 1154-1162.

30. Levi-Montalcini R. In Praise of Imperfection. Basic book, New York, 1988.

31. Levi-Montalcini R. The Saga of the Nerve Growth Factor. World Scientific Series in 20th Century Biology. Volume 3. World Scient Publish, Singapore 1997.

32. Levi-Montalcini R. Senza Olio e Contro Vento. Baldini e Castoldi Editor. 1996.
33. Levi-Montalcini R. L'asso nella Manica. Brandelli Maldini and Castoldi Editors. 1998.

34. Levi-Montalcini R. Il Cantico di Una Vita. Raffaello Cortina Editore. 2000.

35. Marinova TT, Velikova KK, Petrov DB, Kutev NS, Stankulov IS, Chaldakov GN, Triaca V, Manni L, Aloe L. Structural and ultrastructural localization of NGF and NGF receptors in the thymus of subjects affected by myasthenia gravis. Autoimmunity 2004;37:587-592.

36. Mantyh PW, Koltzenburg M, Mendell LM, Tive L, Shelton DL. Antagonism of nerve growth factor-TrkA signaling and the relief of pain. Anesthesiology 2011;115:189204.

37. Meloni M, Caporali A, Graiani G, Lagrasta C, Katare $\mathrm{R}$, Van Linthout $\mathrm{S}$, et al. Nerve growth factor promotes cardiac repair following myocardial infarction. Circ Res 2010;106:1275-1284.

38. Ochodnický P, Cruz CD, Yoshimura N, Michel MC. Nerve growth factor in bladder dysfunction: contributing factor, biomarker, and therapeutic target. Neurourol Urodyn 2011; 30:1227-1241.

39. Romon R, Adriaenssens E, Lagadec C, Germain E, Hondermarck H, Le Bourhis X. Nerve growth factor promotes breast cancer angiogenesis by activating multiple pathways. Mol Cancer 2010; 9:157. doi: 10.1186/14764598-9-157.

40. Sofroniew MV, Howe CL, Mobley W. Nerve growth factor signalling, neuroprotection, and neural repair. Ann Rev Neurosci 2001; 24: 1217-281.

41. Sornelli F, Fiore M, Chaldakov GN, Aloe L. Adipose tissuederived nerve growth factor and brain-derived neurotrophic factor: results from experimental stress and diabetes. Gen Physiol Biophys 2009; 28:179-183.

42. Weeraratna AT, Arnold JT, George DJ, DeMarzo A, Isaacs JT. Rational basis for Trk inhibition therapy for prostate cancer. Prostate 2000; 45:140-148.

43. Yuen EC, Mobley WC. Therapeutic potential of neurotrophic factors for neurological disorders. Ann Neurol 1996; 40:347-354. 